\title{
Detecting circulating antibodies by controlled surface modification with specific target proteins: Application to malaria.
}

Ana R. Cardoso ${ }^{1, a)}$, Gustavo Cabral-Miranda ${ }^{2, a)}$, Arturo Reyes-Sandoval ${ }^{2)}$, Martin F Bachmann ${ }^{2,3}$ and

\author{
M. Goreti F. Sales ${ }^{1, *}$ \\ ${ }^{1}$ BioMark/CINTESIS-ISEP, School of Engineering of the Polytechnique School of Porto, Portugal \\ ${ }^{2}$ The Jenner Institute, Nuffield Department of Medicine, Centre for Cellular and Molecular Physiology (CCMP); \\ University of Oxford; UK \\ ${ }^{3}$ Immunology, RIA, Inselspital, University of Bern, Switzerland
}

a) Equal contribution as first author.

*Correspondence to: BioMark-Cintesis/ISEP, Instituto Superior de Engenharia do Porto, R. Dr. António Bernardino de Almeida, 341, 4200-072 Porto, Portugal.

E-mail addresses: goreti.sales@gmail.com, mgf@isep.ipp.pt (M.G.F. Sales). 


\section{Abstract}

Sensitive detection of specific antibodies by biosensors has become of major importance for monitoring and controlling epidemics. Here we report a development of a biosensor able to specifically measure antibodies in a drop of unmodified blood serum. Within minutes, the detection system measures presence of antibodies against Plasmodium vivax, a causing agent for malaria. The biosensor consists of of a layer of carbon nanotubes (CNTs) which were casted on a carbon working electrode area of a three-electrode system and oxidized. An amine layer was produced next by modifying the surface with EDAC/NHS followed by reaction with a diamine compound. Finally, the protein fragments derived from $P$. vivax containing well-known antigen sequences were casted on this layer and bound through electrostatic interactions, involving hydrogen and ionic bonding. All these chemical changes occurring at the carbon surface along the biosensor assembly were followed and confirmed by Fourier Transformed Infrared s pectrometry (FTIR) and Raman spectroscopy.

The presence of antibodies in serum was detected by monitoring the electrical properties of the layer, making use of cyclic voltammetry (CV), electrochemical impedance spectroscopy (EIS) and square wave voltammetry (SWV), against a standard iron probe. Overall, the charge-transfer resistance decreased after antibody binding, because there was an additional amount of protein bound to the surface. This hindered the access of the iron redox probe to the conductive support at the electrode surface. Electrical changes could be measured at antibody concentration as low as $\sim 6-50 \mathrm{pg} / \mathrm{L}$ (concentrations in the range of 10-15 M) and as high as $\sim 70 \mu \mathrm{g} / \mathrm{L}$. Specific measurement with low background was even possible in undiluted serum. Hence, this novel biosensor allows assessing serum antibody levels in real time and in un-manipulated serum samples on-site where needed.

Keywords: Biosensor; Immune response detection; Antibodies; Malaria; Electrochemical Measurements. 


\section{Introduction}

Infectious diseases are still emerging worldwide and remain a fundamental health-care and economical challenge (Fauci and Morens, 2012; Jones, et al., 2008, Morens, and Fauci, 2013). While diagnostic tests for a number of viral infectious diseases, such as HIV (Bateganya, at al., 2016; Chamie, et al., 2016; Orkin, et al., 2016; Shahid, 2016) or hepatitis B (Bottero, et al., 2016; Orkin, et al., 2016) and C (Frimpong, et al,. 2016; Harris, et al., 2016; Orkin, et al., 2016) are well established and readily available, this is not the case for a large number of other infectious agents. Particularly prominent examples are several vector-borne diseases (such as Malaria, Zika, Chikungunya, Yellow Fever) as well as air-borne diseases (such as influenza), water-borne diseases (such as cholera, shigellosis, typhoid fever), epidemic meningitis and haemorrhagic fevers (such as Ebola virus disease, Marburg virus disease). It is the declared goal of leading health care institutions, such as the World Health Organization (WHO), to increase the global capacity to build capacity to mount a rapid, predictable and effective response to major epidemic and pandemic threats. This requires the implementation of programs that increase preparation, surveillance and effective responses to disease outbreaks (Minikel, et al. 2016; WHO, 2014). Overall, these goals demand novel technologies, systems, and techniques that may increase the efficiency of disease recognition, diagnosis, intervention and control.

Among the methods available for malaria diagnosis, the clinical diagnosis remains the dominant tool to recognize malaria, a rather ineffective method, however, as the clinical picture is often dominated by non-specific symptoms, such as fever and malaise (Genton, et al. 1994; Tjitra, et al. 1999; Nankabirwa, et al. 2009). Additional diagnostic tools include microscopic examination of blood samples or polymerase chain reaction (PCR) for parasite detection (Moody, 2002; Bailey, et al. 2013). Both involve rather sophisticated equipment often unavailable in endemic areas. Serological tests can also be used to detect antibodies against malaria parasites. This can be done either using indirect immunofluorescence (IFA) or enzyme-linked immunosorbent assay (ELISA) (Bailey, et al. 
2013, Michael and Wilson, 2013). Overall, these assays work well in controlled clinical trials but require an expensive laboratory structure for routine use in endemic areas. Novel, cost-effective and easy to implement and use methods are therefore required to improve diagnosis of malaria and other diseases in the field.

One possible alternative towards the emerging need of point-of-care diagnosis, manage and control of epidemic diseases may be to create a simple device capable of monitoring the human immune response against the involved microorganisms (Chattopadhyay, et al., 2014; Fernández-Ruiz, et al. 2014, Furmana and Davis, 2015). The presence of an immune response and the levels of antibodies circulating in the body are often a crucial tool to help assessing a patient`s individual condition and disease history as well understanding the mechanics of the regional and global spread of the pathogen (Agarwal and Cunningham-Rundles, 2007; Li, et al., 2015; Sorci, et al., 2013). As far as we know, there is currently no technique readily available to perform such monitoring in real time under field conditions. In this context, the portability and simplicity of procedure is at the heart of the problem - a challenge that may be solved by cutting edge biosensing technologies (Caliendo, et al., 2013; D'Orazio, 2011; Singh, et al., 2014; Zhang, et al. 2010). The current developments in nanotechnology have led to the generation of biosensors with many advantageous features when compared to conventional methods. These include low cost, portability, excellent sensitivity/selectivity features, simplicity of use and ability for detection in real time (Gao, et al., 2016; Godonoga, et al., 2016; Speicher and Pantel, 2014, Wu, et al., 2016).

There are few biosensors reported in the literature for tracking Malaria (reviewed recently by Rodovalho et al., 2015 and Brince-Paul et al., 2016. A brief description of their performance is given in table 1. Most methods aim at the detection of Plasmodium falciparum Histidine-rich protein 2 (Sharma et al., 2008; Sharma et al., 2011; Brince-Paul et al., 2016). Other reports describe the detection of DNA fragments in malaria-infected blood (Ittarat et al., 2013) or measurement of Plasmodium lactate dehydrogenase activity (Lee at al., 2012). As far as we know, there is a single 
method devoted to the determination of antibodies against Plasmodium falciparum in the blood (Sharma et al., 2010) and this method detected antibodies in rat serum down to a dilution of $1: 102400$.

In the current study, we report a simple sensing layer that is capable of detecting and quantifying the human immune response against a given pathogen or parasite related to worldwide epidemic diseases. It is based on immobilization of specific antigenic regions to which antibodies circulating in the body after infection can bind with high specificity. The sensing layer is assembled on screenprinted electrodes to ensure portability and on-site analysis. This new principal is applied herein as proof-of-concept to Malaria, one of the most prevalent infectious diseases having a yearly toll of more than 438000 killed by the parasite (WHO, 2015).

The new biosensor presented here enables point-of-care detection of antibodies against two important antigens of $P$. vivax infection, CSP (Circumsporozoite protein) and TRAP (Thrombospondin related anonymous protein) (Muller, 1993; Prudêncio, 2006; Sinnis and Sim, 1997). The biosensor was designed by placing a protein with the two epitope regions for the indicated antigens on a conductive nanotube surface. Antibodies against both antigens could be measured in a sensitive way and from undiluted serum, indicating that this novel type of biosensor may be readily used in field applications. Furthermore, it is probable that it may be used not only for the detection of anti-malaria antibodies but also for monitoring antibody responses against other emerging global threats such as Ebola- or Zika-virus, provided that additional experiments are made to confirm such extended application and a portable apparatus can be designed.

\section{Experimental Section}

\subsection{Procedures and materials involved in the protein production}


The chimeric CSP 210-247 was cloned in open reading frame of the central repeats from VK247 (GenBank P08677) and VK210 (GenBank M69059.1) isoforms, between N and C terminal regions from Salvador 1 strain of $P$. vivax (GenBank 5472322) into pHLsec mammalian expression vector and expressed by HEK 293 T cells. PvTRAP was synthesised by Geneart ${ }^{\mathrm{TM}}$, followed by cloning into pHLsec to produce protein. Essential details of this synthesis may be found in the supplementary section (S1 and S2).

\subsection{Apparatus}

The electrochemical measurements were performed with a Metrohm Autolab, PGSTAT320N, potentiostat/galvanostat, controlled by NOVA 1.11 software. The carbon-screen printed electrodes (Carbon-SPEs) were of commercial origin, produced by DropSens (DRP-C110) - any other carbon SPEs may also be applied herein. The three electrode system of the carbon-SPEs contained: i) a counter electrode made of carbon; ii) a reference electrode made of silver; and iii) a carbon working electrode of $4 \mathrm{~mm}$ diameter. All electrical connections were made in silver. The Carbon-SPEs were interfaced with the potentiostat by means of a switch box (also from DropSens). A representation/photograph of the equipment, SPE and resulting signals has been shown in Figure S1.

\subsection{Reagents}

All chemicals were of analytical grade and water was deionised (conductivity $<0.1 \mu \mathrm{S} / \mathrm{cm}$ ) or ultrapure Mili-Q laboratory grade. The chemical reagents including potassium hexacyanoferrate III $\left(\mathrm{K}_{3}\left[\mathrm{Fe}(\mathrm{CN})_{6}\right]\right)$, potassium hexacyanoferrate II $\left(\mathrm{K}_{4}\left[\mathrm{Fe}(\mathrm{CN})_{6}\right]\right)$ trihydrate, were obtained from RiedeldeHäen; Ethylenediamine was obtained from Merck, $N^{\prime}$-ethyl-N'-(3-Dimethylaminopropyl) carbodiimide hydrochloride (EDAC) was obtained from Alfa Aesar, $N$-Hydroxysuccinimide (NHS) was obtained from Fluka; $N$-Dimethylformamide (DMF) was obtained from Analar Normapur; 
Carboxylated CNTs were obtained from Sigma; and Phosphate Buffer Saline (PBS) was obtained from Amresco.

\subsection{Electrochemical Procedures}

The electrochemical studies involved CV, EIS and SWV assays performed in the iron redox probe solution and under the following electrochemical conditions. CV assays were made by scanning potentials from -0.3 to $+0.7 \mathrm{~V}$, at $50 \mathrm{mV} / \mathrm{s}$. EIS assays were established under a formal potential of $+0.14 \mathrm{~V}$ using a sinusoidal potential perturbation with amplitude $0.01 \mathrm{~V}$ and 50 frequency values, logarithmically distributed from 0.1 to $100000 \mathrm{~Hz}$; the data obtained was fitted to a Randles equivalent circuit using 1.11 Nova Software from Autolab. SWV assays were conducted from -0.3 to $+0.7 \mathrm{~V}$, with a frequency of $25 \mathrm{~Hz}$ and the step height of to $50 \mathrm{mV}$.

Regarding specifically EIS data, Nyquist plots was used to plot the obtained spectra showing the frequency response of the electrolyte system and plotting the imaginary component $\left(Z^{\prime}\right.$ ') of the impedance against its real component $\left(Z^{\prime}\right)$. EIS data was fitted into the typical Randle's equivalent circuit, which matched the physiochemical processes occurring at the carbon electrode surface. This circuit was composed of several elements: resistance of the solution phase (Rs), capacitance of the double layer $\left(\mathrm{C}_{\mathrm{dl}}\right)$, charge-transfer resistance $\left(\mathrm{R}_{\mathrm{ct}}\right)$ at the electrode surface and Warburg diffusion element $(\mathrm{W})$. $\mathrm{R}_{\mathrm{ct}}$ was given by the diameter of the semicircle obtained in the plot.

All electrochemical readings were made by casting a volume of about $\sim 80 \mu \mathrm{L}$ of the solution under analysis on the three-electrode system of the SPE. This volume was enough to cover all electrodes, which is a requirement of the electrochemical analysis. The CV, SWV and EIS measures were made immediately after. 
The overall changes made on the carbon electrode area are presented in Figure 1. In brief, a suspension of $1 \mathrm{mg}$ of carboxylated CNTs in DMF was dispersed in ultrasounds for $1 \mathrm{~h}$. After that, a volume of $6 \mu \mathrm{L}$ of this suspension was casted on the carbon electrode area and let dry at $70{ }^{\circ} \mathrm{C}$ for 30 minutes. This procedure was repeated three times. The carboxylic groups on the surface were activated by casting $6 \mu \mathrm{L}$ of a solution containing EDAC $(0.025 \mathrm{M})$ and NHS $(0.0125 \mathrm{M})$ freshly prepared in PBS and mixed for 1h30, at room temperature. This solution was removed and replaced by $6 \mu \mathrm{L}$ of a $0.02 \mathrm{M}$ ethylenediamine solution in PBS and cast for 60 minutes. The peptide with the antigen regions CSP210-247 was immobilized by casting $6 \mu \mathrm{L}$ of a $2.8 \mu \mathrm{g} / \mathrm{ml}$ peptide CSP210-247 solution prepared in PBS (pH 7.4). This solution was let stand for 45 minutes at $37^{\circ} \mathrm{C}$. The sensing layer was then washed with PBS. Antibody binding was accomplished by casting standard solutions of Anti-CSP 210 and Anti-CSP 247 of increasing concentrations. Each standard was incubated for 30 minutes at $37^{\circ} \mathrm{C}$. Similarly, the positive serum samples were tested at several dilutions and the response of the sensing layer was evaluated to each degree of dilution.

In detail, the first stage of modification includes the casting of carboxylated CNTs onto the carbon working electrode (Figure 1A). Only the necessary volume to cover the area of the working electrode was casted, thereby avoiding changes on counter or reference electrodes. This procedure was repeated three times. Each drop was allowed to dry before adding a new one.

The resulting surface was then altered with the purpose of generating an amine layer. This was done in two stages. The first stage consisted on activating the $-\mathrm{COOH}$ functions on the CNTs with EDAC reaction, yielding the formation of a highly reactive $O$-acylisourea intermediate. This was followed by the immediate reaction with NHS, which produced an activated ester that was sufficiently unstable to undergo a nucleophilic substitution by any amine group (Figure 1B) (Jiang et al., 2004). The second stage achieves amination of the surface (Figure $1 \mathrm{C}$ ) by the addition of a di-amine compound to the activated carboxylic surface. The presence of this amine layer on the carbonmodified electrode was confirmed by a significant $\mathrm{R}_{\mathrm{ct}}$ increase in EIS, accounting the presence of 
non-conductive species over the surface. As observed before, SWV data recorded is more sensitive to concentration changes, while the changes in $\mathrm{CV}$ were less pronounced

The sensing layer was now ready to receive the proteins containing the antigenic epitopes to which the antibodies would bind. For this purpose, the protein solution was casted on the surface and incubated for 30 minutes (Figure 1D).

The concentration of protein required at the surface and the time required for this binding to occur were also evaluated. It was important to ensure at this stage that the sensing surface was fully covered by protein in order to produce a sensitive and from chip-to-chip reproducible response against the antibodies in sera, and to reduce non-specific binding to the surface of other compounds present in sample matrix. To this end, the protein concentration was changed from 0.56 to $28 \mu \mathrm{g} / \mathrm{mL}$. The time given for protein binding was also varied within 30 and 60 minutes, as this may influence required protein concentration. Optimal conditions were found for a protein incubation along 45 minutes.

\subsection{Evaluation of the analytical performance}

The performance of each sensing layer was evaluated by incubating increasing concentrations of standard antibody solutions. This was done for single standard solutions of antibody (Anti-CSP 210 or Anti-CSP 247) and combined solutions (Anti-CSP 210 and Anti-CSP 247), all prepared in PBS buffer. The Anti-CSP 210 and Anti-CSP 247 concentrations ranged $9.59 \times 10^{-11}$ to $1.70 \times 10^{-5} \mu \mathrm{g} / \mu \mathrm{L}$, prepared in PBS, lying within the linear range. All the assays were conducted in duplicates and the measurements were made by EIS. After incubation in each antibody concentration tested, the sensing layer was washed and evaluated in terms of electrical properties, by checking its response against a standard solution of $5.0 \times 10^{-3} \mathrm{M} \mathrm{K}_{3}\left[\mathrm{Fe}(\mathrm{CN})_{6}\right]$ and $5.0 \times 10^{-3} \mathrm{M} \mathrm{K}$ [ $\left[\mathrm{Fe}(\mathrm{CN})_{6}\right]$, prepared in PBS buffer, $\mathrm{pH} 7.4$. 
The LOD was calculated as $\mathrm{X}+3 \sigma$, where $\mathrm{X}$ was the average value of EIS or SWV for blank signals (obtained in the absence of Anti-CSP 247, Anti-CSP 210 and Anti-CSP 210-247) and $\sigma$ was the known standard deviation of EIS or SWV for the blank signal (Harvey, 2000). All assays were conducted in duplicates.

\subsection{Analysis of samples}

The antibodies were assessed in different types of sera samples: One negative serum (acting as control and without Anti-CSP) and two sera containing Anti-CSP 210-247, but with different antibody levels. All sera were tested directly on the sensory element. The negative serum was also used to prepare standard solutions of antibodies Anti-CSP 210-247 (1:100 diluted in PBS buffer) in order to produce a calibration of the sensing layer in a serum background. The negative serum diluted in PBS buffer was also employed to carry out all necessary dilutions of the positive sera.

\section{Results and discussion}

\subsection{CSP 210-247 chimeric protein production and purification}

The CSP protein of $P$. vivax occurs in two major forms produced by 2 different parasite strains. In order to be able to detect both forms, a chimeric CSP protein was produced expressed in HEK 293T cells and purified over a nickel column. The purity of the CSP protein was assessed by $12.5 \%$ SDSPAGE followed by visualization with Coomassie brilliant blue or Silver stain and was found to be $>90 \%$. Protein identity was confirmed by Western Blot using a His-tag specific antibody and CSP210 and CSP247 monoclonal antibodies obtained from the Malaria Research and Reference Reagent Resource Centre (MRA). 


\subsection{Assembly the sensing layer}

A schematic representation of the steps used for the assembly of the sensing layer for capturing CSP 210 and CSP 247-specific antibodies is shown in Figure 1. In a first step, the commercial SPEs were modified by CNTs to enhance the electrical properties of the layer which was followed by amidation and CSP was bound to the amine layer by electrostatic interactions. The maximum amount of CSP on the sensing area was achieved by casting $2.8 \mu \mathrm{g} / \mathrm{mL}$ of protein for a period of 40 minutes.

All chemical modifications made to generate the sensing layer were confirmed by following the changes in the typical CV, EIS and SWV records (Figure 2A, 2B and 2C) of a standard iron redox probe. EIS data is presented as Nyquist plots and fitted into the typical Randle's equivalent circuit, where $\mathrm{R}_{\mathrm{ct}}$ is given by the diameter of the semicircle obtained in the plot.

The obtained electrical signals showed that the electrical properties of the sensing layer were improved after casting carboxylated CNTs onto the carbon working electrode. The efficiency of this process was revealed most clearly by EIS assays; SWV data was also sensitive to this modification, while $\mathrm{CV}$ records were not as sensitivity. The next step consisted on the formation of an amine layer, to which the CSP protein was expected to bind with high affinity. This amine layer was linked to an $\mathrm{R}_{\mathrm{ct}}$ increase and lower current produced by SWV, as this new layer did not hold special conductivity features. As expected, the adsorption of the CSP protein to this amine layer was also linked to an additional $\mathrm{R}_{\mathrm{ct}}$ increase and current decrease in SWV assays. In general, $\mathrm{CV}$ data changes along the assembly procedure were not as sensitive as EIS or SWV.

\subsection{Antibody interaction with the sensing layer}


The sensing layer in Figure 1E was designed to be able to bind to Anti-CSP 210 and Anti-CSP 247 in serum by establishing a strong and selective binding. As antibody binding may be more effective at body temperature, the biosensor was first tested at $37^{\circ} \mathrm{C}$.

To this end, a concentration of $0.17 \mathrm{ng} / \mathrm{mL}$ of monoclonal antibody standard solution was incubated first on the sensing layer, at $37^{\circ} \mathrm{C}$ for 30 minutes. The antibody binding was confirmed by a peak potential shift in $\mathrm{CV}$ assays, linked to a wider potential range of peak separation (Figure 2D), a significant $R_{c t}$ increase of the sensing area in the Nyquist plots (Figure 2E), and a decrease of the peak current in SWV assays (Figure 2F). These signals were stable after consecutive washing periods and readings by the iron probe, thereby confirming the inert and stable interaction established between protein and antibody.

The sensing layer was tested again with a higher antibody-concentration in order to know if the electrical changes observed were concentration dependent - a necessary feature to generate quantitative data from serum samples. A concentration of antibody of $1.7 \mathrm{ng} / \mathrm{mL}$ was selected for this purpose. As may be seen in Figures 2D, 2E and 2F, large electrical alterations were observed in EIS readings. The charge-transfer resistance of the sensing layer increased because an additional amount of protein (bound antibody) remained on the surface and hindered the access of the iron redox probe to the conductive support at the electrode surface. CV and SWV assays also detected additionally bound antibody, but the electrical changes were less pronounced than those in EIS. In addition, the oxidation peak of iron in the CV assays displayed a peak potential shift to lower values, which was not clearly consistent with the presence of the protein on the surface. Thus, SWV and EIS were found better electrochemical approaches for generating reliable quantitative data.

\subsection{Analytical performance of biosensor}


The analytical performance of the sensing layer assembled on commercial SPEs was evaluated by EIS and SWV measurements against increasing antibody concentrations, plotted as calibration curves. While EIS seems to produce more sensitive results, SWV proved to be the faster approach. The solutions used for this purpose contained monoclonal anti-CSP 247 or anti-CSP 210, or antiCSP 247-210, i.e. each antibody was tested individually as well as in combination in the same solution. The concentrations of these antibodies ranged from $95.9 \mathrm{fg} / \mathrm{mL}$ to $17 \mathrm{ng} / \mathrm{mL}$ and all solutions (total concentration in the case of the combined antibodies, 1:1 ratio) were prepared in PBS buffer.

In general, all EIS measurements (Figure 3) showed that increasing concentrations of Anti-CSP 247, Anti-CSP 210 and Anti-CSP 210-247 increased the charge-transfer resistance of the probe at the sensing layer. This was observed by the increasing diameter of the semicircles in the Nyquist plots and accounted additional amounts of protein bound to the surface. A good linear trend was obtained for $\mathrm{R}_{\mathrm{ct}}$ against logarithm of antibody concentration (Anti-CSP 247, Anti-CSP 210 or Anti-CSP 247210), over a wide concentration range, from $95.9 \mathrm{fg} / \mathrm{mL}$ up to $17 \mathrm{ng} / \mathrm{ml}$. Higher concentrations would be leading to the saturation of the sensing layer, while lower concentrations were probably not detected, as little differences were observed between the signals of the blank and the first standard of the calibration curve. The reproducibility of the sensing system was excellent, as confirmed by performing two independent calibrations with two independent separately assembled devices. For each specific antibody solution under study, the standard deviation of the slope of the calibration was reproducibly $<2.2 \%$. Overall, similar calibration curve patterns were observed for all antibodies, both in single and combined solutions (table S2), indicating that they have high and similar affinities for the immobilized protein. Combining all calibrations (duplicates and different antibody solutions), the slope values were $221 \pm 11.3 \Omega /$ decade, corresponding to about $5 \%$ changes in all these. This data clearly confirm the high precision of the system in terms of reproducibility, i.e. the standards may be changed as well as the device, but a $5 \%$ maximum deviation is observed. 
The calibration of the sensing layers by SWV (Figure S2) showed a similarly consistent behaviour as observed for EIS calibrations. The increased resistance occurring at the surface after antibody binding was revealed by a decrease of the current generated by the iron redox probe. Not all antibody solutions were tested in this study because there was not enough stock solution to prepare all necessary standards. As in EIS, no significant differences were observed when standard solutions of Anti-CSP 210 (Figure S2-A and S1-B) or Anti-CSP 210-247 (Figure S2-C and S2-D) were used. The replicate calibrations using new SPEs also confirmed the high reproducibility of the analytical response.

Overall, both EIS and SWV showed strong sensitivity for both antibody solutions. The described sensing layer assembled on different batches of SPEs offered reproducible data and no significant variations were produced by the use of different calibrating solutions.

\subsection{CSP assay in sera samples}

To obtain information on the performance of the biosensor in a more realistic "real-life" situation, we evaluated its analytical output using four different types of mouse sera by plotting calibration curves as $\mathrm{R}_{\mathrm{ct}}$ (in EIS) and current intensity $(I$, in SWV) against logarithm of dilution. The first tested serum was a pre-immune negative control without Anti-CSP 210-24 antibodies. The second serum consisted of the negative serum spiked with different concentrations of both monoclonal antibodies (Anti-CSP 210-247), which was used as a calibration plot for obtaining quantitative data from positive sera samples. The third serum tested was found weakly positive by ELISA while the fourth serum was highly positive for polyclonal anti-CSP 210-247 antibodies. A detailed description of these assays is presented next.

3.5.1 Blank serum samples 
Blank serum samples were tested to identify the ability of the device to distinguish the antibodies related to Malaria from other components in serum. The sensing layer was first incubated in serum with a high degree of dilution and subsequently with decreasing dilution levels. Figure 4A and 4B depict signals obtained with this negative serum and no response in all measurements was observed, indicating that the biosensor did not pick up non-specific signals.

\subsubsection{Spiked serum samples}

The analyse the effect of serum on antibody recognition, monoclonal antibodies were spiked into sera from naïve animals and electrical signals generated by the sensing layer were analysed. Figures 5C and 5D depict the responses induced by negative serum spiked with monoclonal antibodies. The linear trend had a slope of $152.86 \Omega /$ decade, which was similar to the one observed in buffer solutions. The response of the sensing layer followed the concentration of antibody from $95.9 \mathrm{fg} / \mathrm{ml}$ to $17 \mathrm{ng} / \mathrm{ml}$, thereby allowing its application to real conditions.

\subsubsection{Positive sera samples}

First, assays were made with different serum samples that produced weak or strong responses in ELISA experiments. These samples were serially diluted in naive serum and incubated consecutively in the sensing layer (higher dilution to lower dilution). Each solution was allowed to equilibrate for 30 minutes on the sensing layer. After that, the sensing layer was washed and followed by the iron probe reading, making use of both EIS and SWV techniques.

Figures S3-A and S3-B show the sensitive response of the sensor to each of the diluted sera solutions (EIS and SWV, respectively), prepared from serum weakly positive in ELISA. The concentration of antibody in each of these dilutions was estimated using the calibration curve prepared with monoclonal antibodies in naïve serum (section 3.5.2). It was interesting to observe that all these 
dilution levels yielded similar concentrations for the original sample. The average value of antibody in serum was $3.2 \pm 0.1 \mathrm{ng} / \mu \mathrm{L}$, corresponding to a standard deviation of $3.1 \%$. So the sensing layer showed similar accuracy all over the wide linear range observed, also yielding precise data as confirmed by the small standard deviation.

The strongly positive serum exhibiting higher levels of polyclonal anti-CSP 210-247 antibodies in ELISA was also serially diluted. Overall, the sensing layer showed a similar behaviour as observed with the weakly positive serum (Figures S3-C and S3-D). As before, each dilution degree yielded similar levels of antibodies on the original samples. The average value was $20.9 \pm 0.5 \mathrm{ng} / \mu \mathrm{L}$, corresponding to a $2.4 \%$ standard deviation. The accuracy and the precision of the device are therefore confirmed for different levels of polyclonal antibodies.

\subsection{Direct sera readings}

Whether it was possible to measure antibody levels in undiluted sera was addressed next (Figure 5). Additional sera samples were used in this study. These samples contained different levels of antibodies as assessed by ELISA $(1++, 2++, 3++$ higher concentration; and 4+, 5+, 6+ medium concentration) in accordance with the schedule of vaccination, which used different doses of vaccines (with or without adjuvants) and time of blood sampling, reflecting natural variations seen after vaccination. As control, a group of mice was immunized with only PBS (negative control; samples 7-, 8-, 9- and 10-).

These results demonstrated that the biosensor was able to measure background free antibody levels in non-diluted sera, a pre-requisite for field-use. As may be seen in Figure 5A, all negative sera samples did not change the blank signal significantly and the sera samples with different levels (+ or $++)$ were grouped in terms of signal location. Using the calibration curve of the spiked blank serum 
samples, the concentrations deduced for these additional sera were: $308 \mathrm{ng} / \mathrm{ml}(1++) ; 37.4 \mathrm{ng} / \mathrm{ml}$ $(2++) ; 2.89 \mathrm{ng} / \mathrm{ml}(3++) ; 119 \mathrm{pg} / \mathrm{ml}(4+) ; 22.3 \mathrm{pg} / \mathrm{ml}(5+)$ and $203 \mathrm{fg} / \mathrm{ml}(6+)$.

\subsection{Extension to a second malaria antigen}

In order to reveal whether the assembly of this sensing layer could be extended to other antigens, the same procedure was applied to a different protein of $P$. vivax. PvTrap was selected for this purpose since it is also an important protein in the sporozoite of plasmodium, mainly responsible for induction of T cell responses (Bauza, et al., 2014).

As shown in Figure S4, a biosensor generated with PvTRAP was able to sensitively pick up antiTRAP antibodies in a similar way as shown above for CSP. No concentrations were calculated this time, because there was no standard antibody available to perform a calibration curve. Still, the electrical changes generated by serial sample dilution confirmed the high sensitivity of the system for anti-PvTrap (detecting levels of antibodies even after diluting the original serum by factor of $1.7 \times 10^{7}$ ), over a wide concentration range (linear range was observed between $300 \times$ to $1.7 \times 10^{7} \times$ dilutions). These findings confirm the high efficiency of this new way of producing a sensing layer against a circulating antibody and demonstrate that the here designed biosensor can be used in a general manner.

Furthermore, a minimum of 10 months is indicated as lifetime for these devices. The ability of the sensors to respond after a long period of preparation was tested for PvTRAP-based sensors, stored in the refrigerator, under humid conditions. The results obtained pointed out that the sensor kept its ability to respond to the anti-PvTRAP in real serum, with similar sensitivity (Figure S5). It is important to highlight that the devices have been produced and stored at $+4^{\circ} \mathrm{C}$ in the context of the lifetime study (please see additional details in the supplementary section, S.6). 
From a durability perspective, and assuming this feature as the time along which the device may be useful after being in use, it is important to highlight that the proposed biosensor is a single use device. Once the antibody binds the sensing layer, it cannot be removed from the surface. So, the device is meant to be disposed-off after a single-use. Under real scenarios, this feature shall not limit the operation of the biosensor, because real samples are in contact with the electrode, and any attempt to reuse it rises health-safety concerns.

\section{Conclusions}

This work describes the development of a highly sensitive and inexpensive sensing layer for the rapid detection of the antibodies that circulate in the blood and signal a specific disease. The assembly of the sensing element was made on a carbon commercial SPE (a generalist carbon surface, of low cost) and involved monolayer modifications of minimum complexity, providing very low detection limits in buffer and in sera, down to the range of $50 \mathrm{fg} / \mathrm{ml}$, which corresponds to a concentration of about $10^{-15} \mathrm{M}$. As polyclonal antibodies usually have affinities of $10^{-9}$ to $10^{-10} \mathrm{M}$, this indicates that the here described sensor detects antibodies at concentrations well below the average affinity of the antibodies. A linear response was observed over a wide range of antibody concentrations, which is an advantageous feature, as initial levels of immune response are easily detected and undesired background effects may be avoided by establishing a higher degree of sample dilution. In addition, analytical readings may be established by EIS or SWV, depending on the technique that is available to perform on-site analysis.

Comparing the current state-of-art techniques, this work describes significant advances. Firstly, there is no other work reporting the detection of antibodies specific for $P$. vivax. Secondly, the here described biosensor is far superior over previously reported systems for $P$. falciparum. Thirdly, the quality and reproducibility of the data is of the highest standards. 
Overall, the simple and sensitive strategy proposed herein is considered a promising approach for the routine field detection of pathogens and control of emerging diseases, hopefully even at the initial stages of disease outbreak. In terms of target(s), the sensing layer may be improved by extending the proposed design to a multiplex approach, where different antigenic proteins are casted over multiple SPEs. This will allow multiple analytical responses from a single serum drop, which could be directed towards a group of diseases or multiple antibodies of the same disease. 


\section{References}

Agarwal, S., \& Cunningham-Rundles, C., 2007. Ann Allergy Asthma Immunol. 99, 281-283.

Bailey, J.W., Williams, J., Bain, B.J., Parker-Williams, J., Chiodini, P.L., 2013. Guideline: The laboratory diagnosis of malaria. Br. J. Haematol. 163, 573-580. doi:10.1111/bjh.12572.

Bauza, K., Malinauskas, T., Pfander, C., Anar, B., Jones, E.Y., Billker, O., Hill, A.V., ReyesSandoval, A., 2014. Infect Immun. 82, 1277-86.

Bateganya, M.H., Sileo, K.M., Wanyenze, R.K., Kiene, S.M., 2016. Public Health 16, 30-5.

Bottero, J., Boyd. A., Gozlan, J., Carrat, F., Lemoine, M., Rougier, H., Varsat, B., Boo, N., CharloisOu, C., Collignon, A., Cha, O., Campa, P., Dhotte, P., Girard, P.M., Lacombe, K., 2016. Eur J Gastroenterol Hepatol 28, 633-9.

Brince Paul, K., Kumar, S., Tripathy, S., Vanjari, S.R.K., Singh, V., Singh, S.G., 2016. A highly sensitive self assembled monolayer modified copper doped zinc oxide nanofiber interface for detection of Plasmodium falciparum histidine-rich protein-2: Targeted towards rapid, early diagnosis of malaria. Biosens. Bioelectron. 80, 39-46. doi:10.1016/j.bios.2016.01.036

Caliendo, A.M., Gilbert, D.N., Ginocchio, C.C., Hanson, K.E., May, L., Quinn, T.C., Tenover, F.C., Alland, D., Blaschke, A.J., Bonomo, R.A., Carroll, K.C., Ferraro, M.J., Hirschhorn, L.R., Joseph, W.P., Karchmer, T., MacIntyre, A.T., Reller, L.B., Jackson, A.F., 2013. Clin Infect Dis. 57, 13970.

Chamie, G., Clark, T.D., Kabami, J., Kadede, K., Ssemmondo, E., Steinfeld, R., Lavoy, G., Kwarisiima, D., Sang, N., Jain, V., Thirumurthy, H., Liegler, T., Balzer, L.B., Petersen, M.L., Cohen, C.R., Bukusi, E.A., Kamya, M.R., Havlir, D.V., Charlebois, E.D., 2016. Lancet HIV 3, 111-119.

Chattopadhyay, P.K., Gierahn, T.M., Roederer, M., Love, J.C. 2014. Nat Immunol. 15, 128-135.

D'Orazio, P., 2011. Clin Chim Acta. 412, 1749-61.

Fauci, A.S. \& Morens, D.M., 2012. N Engl J Med 366 (5):454-61.

Fernández-Ruiz, M., Kumar, D., Humar, A., 2014. Clin Transl Immunology. 3, 1-11.

Frimpong, J.A., D'Aunno, T., Perlman, D.C., Strauss, S.M., Mallow, A., Hernandez, D., Schackman, B.R., Feaster, D.J., Metsch, L.R., 2016. Trials. 17, 117-28

Furmana, D., \& Davis, M.M., 2015. Vaccine 33, 5271-5281. 
Gao, W., Emaminejad, S., Nyein, H.Y., Challa, S., Chen, K., Peck, A., Fahad, H.M., Ota, H., Shiraki, H., Kiriya, D., Lien, D.H., Brooks, G.A., Davis, R.W., Javey, A., 2016, Nature 529, 509526.

Genton, B., Smith, T., Baea, K., Narara, A., Al-Yaman, F., Beck, H.P., Hii, J., Alpers, M., 1994.Malaria: how useful are clinical criteria for improving the diagnosis in a highly endemic area?. Trans R Soc Trop Med Hyg. 88, 537-41. doi:10.1016/0035-9203(94)90152-X

Godonoga, M., Lin, T.Y., Oshima, A., Sumitomo, K., Tang, M.S., Cheung, Y.W., Kinghorn, A.B., Dirkzwager, R.M., Zhou, C., Kuzuya, A., Tanner, J.A., Heddle, J.G., 2016. Sci Rep. 6, 1-12.

Harris, M., Ward, E., Gore, C., 2016. J Viral Hepat. 23, 479-486.

Ittarat, W., Chomean, S., Sanchomphu, C., Wangmaung, N., Promptmas, C., Ngrenngarmlert, W., 2013. Biosensor as a molecular malaria differential diagnosis. Clin. Chim. Acta. 419, 47-51. doi:10.1016/j.cca.2013.01.010

Jiang, K., Schadler, L.S., Siegel, R.W., Zhang, X., Zhang, H., Terrone, M., 2004. J. Mater. Chem. $14,37-39$.

Jones, K.E., Patel, N.G., Levy, M.A., Storeygard, A., Balk, D., Gittleman. J.L., Daszak, P., 2008. Nature 451, 990-4.

Lee, S., Song, K.M., Jeon, W., Jo, H., Shim, Y.B., Ban, C., 2012. A highly sensitive aptasensor towards Plasmodium lactate dehydrogenase for the diagnosis of malaria. Biosens. Bioelectron. 35, 291-296. doi:10.1016/j.bios.2012.03.003

Li, Z., Peres, A.G., Damian, A.C., Madrenas, J., 2015. Pathogens 4, 793-815.

Minikel, E.V., et al. 2016. Sci Transl Med. 8, 322-9.

Moody, A., 2002. Rapid Diagnostic Tests for Malaria Parasites. Clinical Microbiology Reviews. 15, 66-78. DOI: 10.1128/CMR.15.1.66-78.2002

Morens, D.M. \& Fauci, A.S., 2013. PLOS Pathogens. 9, 1-3.

Müller, H. M., Reckmann, I., Hollingdale, M. R., Bujard, H., Robson, K. J., Crisanti, A., 1993. EMBO J. 12(7): 2881-2889.

Nankabirwa, J., Zurovac, D., Njogu, J.N., Rwakimari, J.B., Counihan, H., Snow, R.W., Tibenderana, J.K., 2009. Malaria misdiagnosis in Uganda--implications for policy change. Malar. J. 8, 66. doi:10.1186/1475-2875-8-66. 
Orkin, C., Flanagan, S., Wallis, E., Ireland, G., Dhairyawan, R., Fox, J., Nandwani, R., O’Connell, R., Lascar, M., Bulman, J ., Reeves, I., Palfreeman, A., Foster, G.R., Ahmad, K., Anderson, J., Tong, C.Y.W., Lattimore, S., 2016. HIV Medicine 17, 222-30.

Prudêncio, M., Rodriguez, A., \& Mota, M.M., 2006. Nat Rev Microbiol. 4, 849-56.

Rodovalho, VR., Alves, LM., Castro, ACH., Madurro, JM., Brito-Madurro, AG., Santos, AR., 2015.

Biosensors Applied to Diagnosis of Infectious Diseases - An update. Austin Journal of Biosensors \& Bioelectronics. 1(3), 1-12.

Shahid, S., 2016. Curr Opin HIV AIDS 11, 6-12.

Sharma, M.K., Agarwal, G.S., Rao, V.K., Upadhyay, S., Merwyn, S., Gopalan, N., Rai, G.P., Vijayaraghavan, R., Prakash, S., 2010. Amperometric immunosensor based on gold nanoparticles/alumina sol-gel modified screen-printed electrodes for antibodies to Plasmodium falciparum histidine rich protein-2. Analyst 135, 608-14. doi:10.1039/b918880k

Sharma, M.K., Rao, V.K., Agarwal, G.S., Rai, G.P., Gopalan, N., Prakash, S., Sharma, S.K., Vijayaraghavan, R., 2008. Highly sensitive amperometric immunosensor for detection of plasmodium falciparum histidine-rich protein 2 in serum of humans with malaria: Comparison with a commercial kit. J. Clin. Microbiol. 46, 3759-3765. doi:10.1128/JCM.01022-08

Sharma, M.K., Rao, V.K., Merwyn, S., Agarwal, G.S., Upadhyay, S., Vijayaraghavan, R., 2011. A novel piezoelectric immunosensor for the detection of malarial Plasmodium falciparum histidine rich protein-2 antigen. Talanta 85, 1812-1817. doi:10.1016/j.talanta.2011.07.008

Singha, R., Das Mukherjee, M., Sumana, G., Gupta, R.K., Sood, S., Malhotra, B.D., 2014. Sensors and Actuators B Chemical 197, 385-404.

Sinnis, P., \& Sim, B.K., 1997. Trends Microbiol 5, 52-58.

Sorci, G., Cornet, S., \& Faivre, B., 2013. Pathogens 2, 71-91.

Speicher, M. R., \& Pantel, K., 2014. Nat Biotechnol. 32, 441-43.

Tjitra, E., Suprianto, S., Dyer, M., Currie, B.J., Anstey, N.M., 1999. Field evaluation of the ICT Malaria P.f/P.v immunochromatographic test for detection of Plasmodium falciparum and Plasmodium vivax in patients with a presumptive clinical diagnosis of malaria in eastern Indonesia. J. Clin. Microbiol. 37, 2412-2417. 
Wilson, M.L., 2013. Laboratory diagnosis of malaria: conventional and rapid diagnostic methods. Arch. Pathol. Lab. Med. 137, 805-11. doi:10.5858/arpa.2011-0602-RA.

WHO, http://www.who.int/mediacentre/factsheets/fs094/en/, assessed by Dec 2015

World Health Organization (WHO). 2014. Twelfth General Programme of Work 2014-2019 http://apps.who.int/iris/bitstream/10665/112792/1/GPW_2014-2019_eng.pdf

Wu. D., Liu, Y., Wang. Y., Hu, L., Ma, H., Wang, G., Wei. Q., 2016. Sci Rep. 6, 205-1.

Zhang, G.J., et al., 2010. Sensors and Actuators B Chemical 146, 138-44. 


\section{Acknowledgements}

The Swiss National Science Foundation (Grant 31003A_149925) and Fundação para a Ciência e Tecnologia, FCT/MEC (through Centro de Investigação em Tecnologias e Serviços de Saúde, IC/04255) are acknowledged for the financial support. G.C.M. acknowledges CNPq (Conselho Nacional de Desenvolvimento Científico e Tecnológico) the post-doctoral scholarship from the Brazil's Science Without Borders program. A.R.S. is supported by a Wellcome Trust career development fellowship No. 097395/Z/11/Z and is a Jenner Investigator. We would like to thank Paul Engeroff for carefully reading the manuscript.

\section{Author contributions}

A.R.A.C. has implemented all experiments regarding the biosensor development, data analysis, and writing the paper draft. G.C.M. has implemented all experiments regarding the protein synthesis and mice vaccination, contributed to the idea of the biosensor and made regular skype meetings to keep up with the work. A.R.S. has contributed with previous knowledge to the protein synthesis. M.F.B. has supervised the protein synthesis and contributed to the writing and revising of the paper. M.G.F.S. has supervised all experiments regarding the biosensor development and contributed to the writing and revising of the paper. 


\section{Legends for Figures}

Figure 1 Schematic illustration of electrochemical biosensor for detection of serum immune response. (A) Oxidation of carbon material; (B) Activated carboxylic acid ends; (C) Ethylenediamine, EDA, addition (D); incubation in CSP protein, 210-247; and (E) binding of the sensing layer to immune antibodies (Anti-210 and Anti-247).

Figure 2 Electrochemical assays for control each step on graphene surface in $5.0 \times 10^{-3} \mathrm{~mol} / \mathrm{L}$ $\left[\mathrm{Fe}(\mathrm{CN})_{6}\right]^{3-}$ and $5.0 \times 10^{-3} \mathrm{~mol} / \mathrm{L}\left[\mathrm{Fe}(\mathrm{CN})_{6}\right]^{4-}$, in PBS buffer with two concentrations of Anti-CSP 247 (0.17 and 1.7 ng/ml). CV (A, D), EIS (B, E) and SWV (C, F).

Figure 3 EIS measurements (A, C and E) and that corresponding calibration curves (B, D and F) in $5.0 \times 10^{-3} \mathrm{M}\left[\mathrm{Fe}(\mathrm{CN})_{6}\right]^{3-}$ and $5.0 \times 10^{-3} \mathrm{M}\left[\mathrm{Fe}(\mathrm{CN})_{6}\right]^{4-}$, in PBS buffer $\mathrm{pH} 7.4$, with different concentrations of Anti-CSP 247 (A and B), Anti-CSP 210 (C and D) and Anti-CSP 210247 (E and F).

Figure 4 EIS (A and C) and SWV measurements (B and D) in $5.0 \times 10^{-3} \mathrm{M}\left[\mathrm{Fe}(\mathrm{CN})_{6}\right]^{3-}$ and $5.0 \times 10^{-3}$ $\mathrm{M}\left[\mathrm{Fe}(\mathrm{CN})_{6}\right]^{4-}$, in PBS buffer $\mathrm{pH} 7.4$, after incubation of blank serum with different dilution degrees (A and B) and blank serum spiked with Anti-CSP 210-247 ranging from $95.9 \mathrm{fg} / \mathrm{ml}$ to $17 \mathrm{ng} / \mathrm{ml}(\mathrm{C}$ and $\mathrm{D})$.

Figure 5 EIS measurements in $5.0 \times 10^{-3} \mathrm{M}\left[\mathrm{Fe}(\mathrm{CN})_{6}\right]^{3-}$ and $5.0 \times 10^{-3} \mathrm{M}\left[\mathrm{Fe}(\mathrm{CN})_{6}\right]^{4-}$, in PBS buffer pH 7.4. (A) Negative sera samples (A) and positive sera samples (B) with higher concentration of antibodies $(1++, 2++$, and $3++)$ or medium concentration of antibodies $(4+, 5+$, and 6+). 
Table 1: List of electrochemical methods used for Malaria detection.

\begin{tabular}{|c|c|c|c|c|c|c|}
\hline Organism & Target & Bioreceptor & Platform & LOD & LR & Ref. \\
\hline $\begin{array}{l}\text { Plasmodium } \\
\text { falciparum and } \\
\text { Plasmodium vivax }\end{array}$ & $\begin{array}{l}\text { DNA fragments of } \\
\text { malaria-infected } \\
\text { blood }\end{array}$ & $\begin{array}{l}\text { Complementary DNA } \\
\text { fragments of malaria } \\
\text { biotinylated probe }\end{array}$ & $\begin{array}{l}\text { Silver/complementary } \\
\text { hydribization }\end{array}$ & - & - & $\begin{array}{l}\text { (Ittarat et } \\
\text { al., 2013) }\end{array}$ \\
\hline $\begin{array}{l}\text { Plasmodium } \\
\text { falciparum and } \\
\text { Plasmodium vivax }\end{array}$ & $\begin{array}{l}\text { Plasmodium lactate } \\
\text { dehydrogenase }\end{array}$ & $\begin{array}{l}\text { single-strand DNA } \\
\text { aptamers for } \\
\text { Plasmodium lactate } \\
\text { dehydrogenase }\end{array}$ & Gold Electrode & $1 \mathrm{pM}$ & 1- $1000 \mathrm{pM}$ & $\begin{array}{l}\text { (Lee et al., } \\
\text { 2012) }\end{array}$ \\
\hline $\begin{array}{l}\text { Plasmodium } \\
\text { falciparum }\end{array}$ & $\begin{array}{l}\text { Antibodies of } \\
\text { Plasmodium } \\
\text { falciparum histidine } \\
\text { rich protein-2 }\end{array}$ & $\begin{array}{l}\text { rabbit anti-PfHRP-2 } \\
\text { antibodies/ PfHRP-2 } \\
\text { complex }\end{array}$ & $\begin{array}{l}\text { SPE/Al2O3 sol-gel/ } \\
\text { AuNPs }\end{array}$ & $\begin{array}{c}\text { Down to } \\
\text { 11× Dil. } \\
(1: 102400) \\
.\end{array}$ & - & $\begin{array}{l}\text { (Sharma et } \\
\text { al., 2010) }\end{array}$ \\
\hline $\begin{array}{l}\text { Plasmodium } \\
\text { falciparum }\end{array}$ & $\begin{array}{l}\text { Plasmodium } \\
\text { falciparum histidine } \\
\text { rich protein-2 }\end{array}$ & $\begin{array}{l}\text { rabbit anti-PfHRP-2 } \\
\text { antibodies }\end{array}$ & $\begin{array}{l}\text { Thioctic acid and 1- } \\
\text { dodecanethiol with } \\
\text { antibody }\end{array}$ & $12 \mathrm{ng} / \mathrm{ml}$ & $15-60 \mathrm{ng} / \mathrm{ml}$ & $\begin{array}{l}\text { (Sharma et } \\
\text { al., 2011) }\end{array}$ \\
\hline $\begin{array}{l}\text { Plasmodium } \\
\text { falciparum }\end{array}$ & $\begin{array}{l}\text { Plasmodium falciparum } \\
\text { Histidine-rich } \\
\text { protein } 2\end{array}$ & $\begin{array}{l}\text { rabbit anti-PfHRP-2 } \\
\text { antibody }\end{array}$ & $\begin{array}{l}\text { Sample, followed by } \\
\text { rabbit anti-mouse } \\
\text { immunoglobulin G- } \\
\text { alkaline phosphatase }\end{array}$ & $8 \mathrm{ng} / \mathrm{mL}$ & $\begin{array}{l}1: 10 \text { and } \\
1: 50 \\
\text { dilutions }\end{array}$ & $\begin{array}{l}\text { (Sharma et } \\
\text { al., 2008) }\end{array}$ \\
\hline $\begin{array}{l}\text { Plasmodium } \\
\text { falciparum }\end{array}$ & $\begin{array}{l}\text { Plasmodium falciparum } \\
\text { Histidine-rich } \\
\text { protein } 2\end{array}$ & Anti-PfHRP-2 antibodies & $\begin{array}{l}\text { Mercaptopropylphosp } \\
\text { honic acid } \\
\text { functionalized copper } \\
\text { doped zinc oxide } \\
\text { nanofibers }\end{array}$ & $6 \mathrm{ag} / \mathrm{mL}$ & $\begin{array}{l}10 \mathrm{ag} / \mathrm{ml}- \\
10 \mu \mathrm{g} / \mathrm{ml}\end{array}$ & $\begin{array}{l}\text { (Brince } \\
\text { Paul et al., } \\
\text { 2016) }\end{array}$ \\
\hline
\end{tabular}




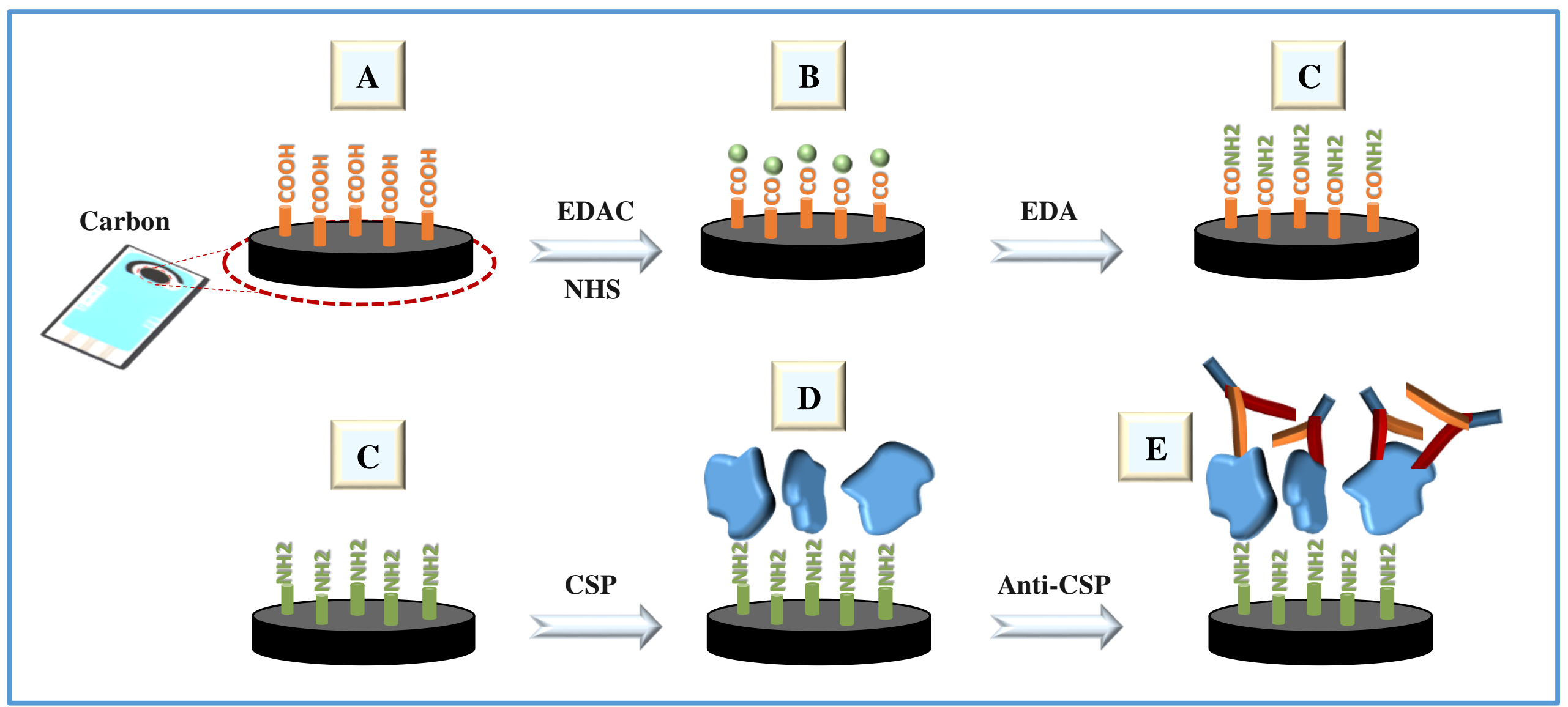

Figure 2 


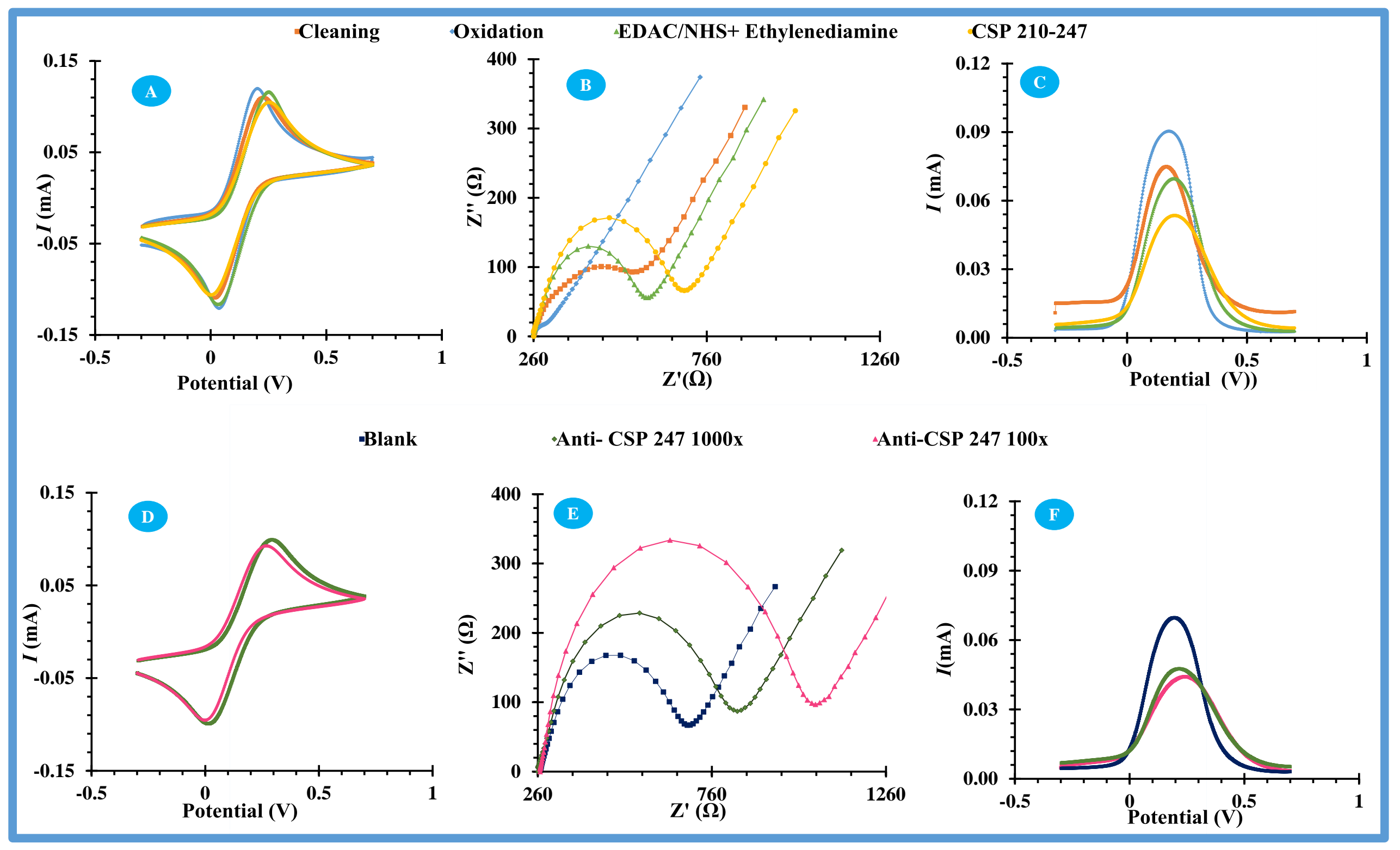

Figure 2 


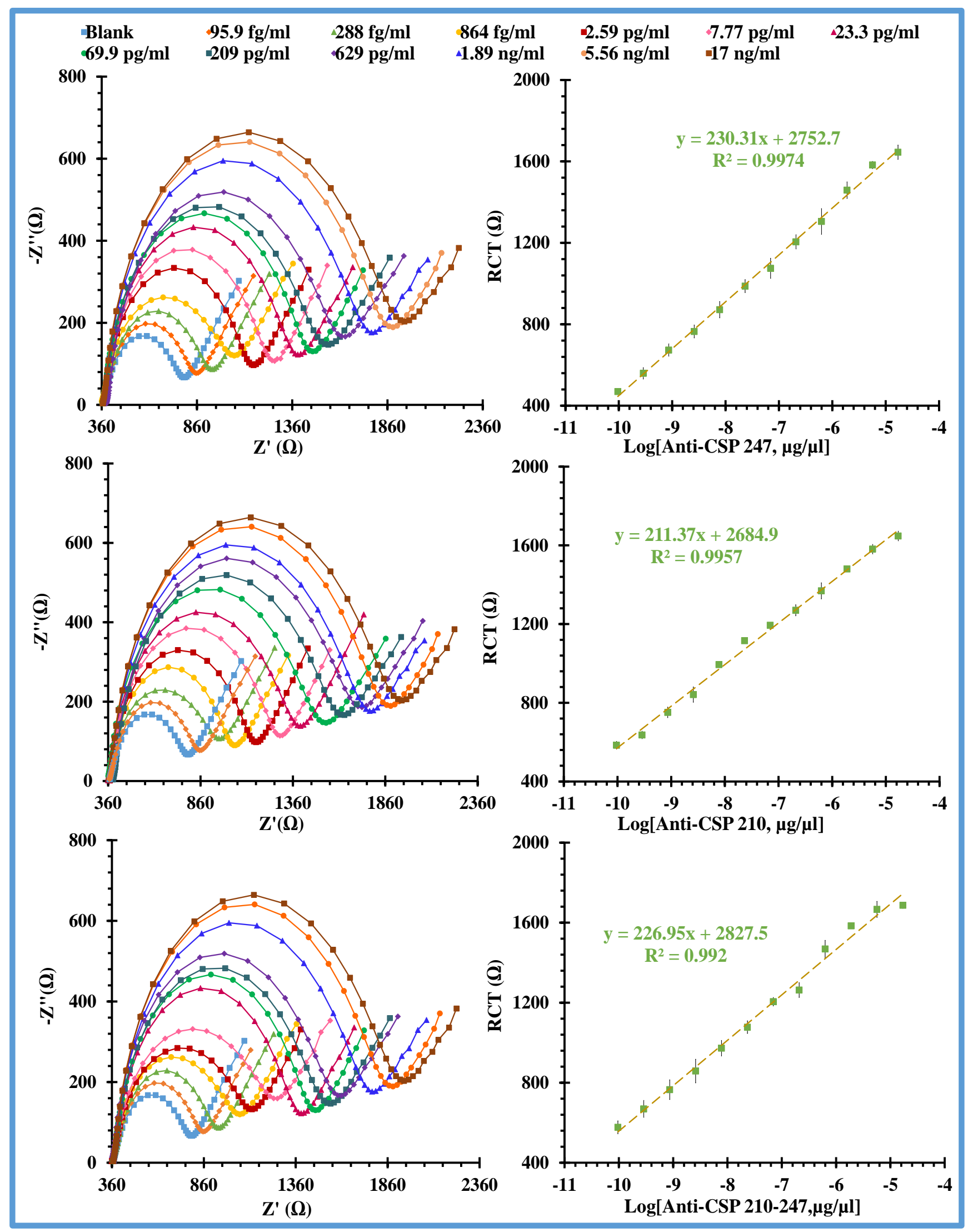

Figure 3 


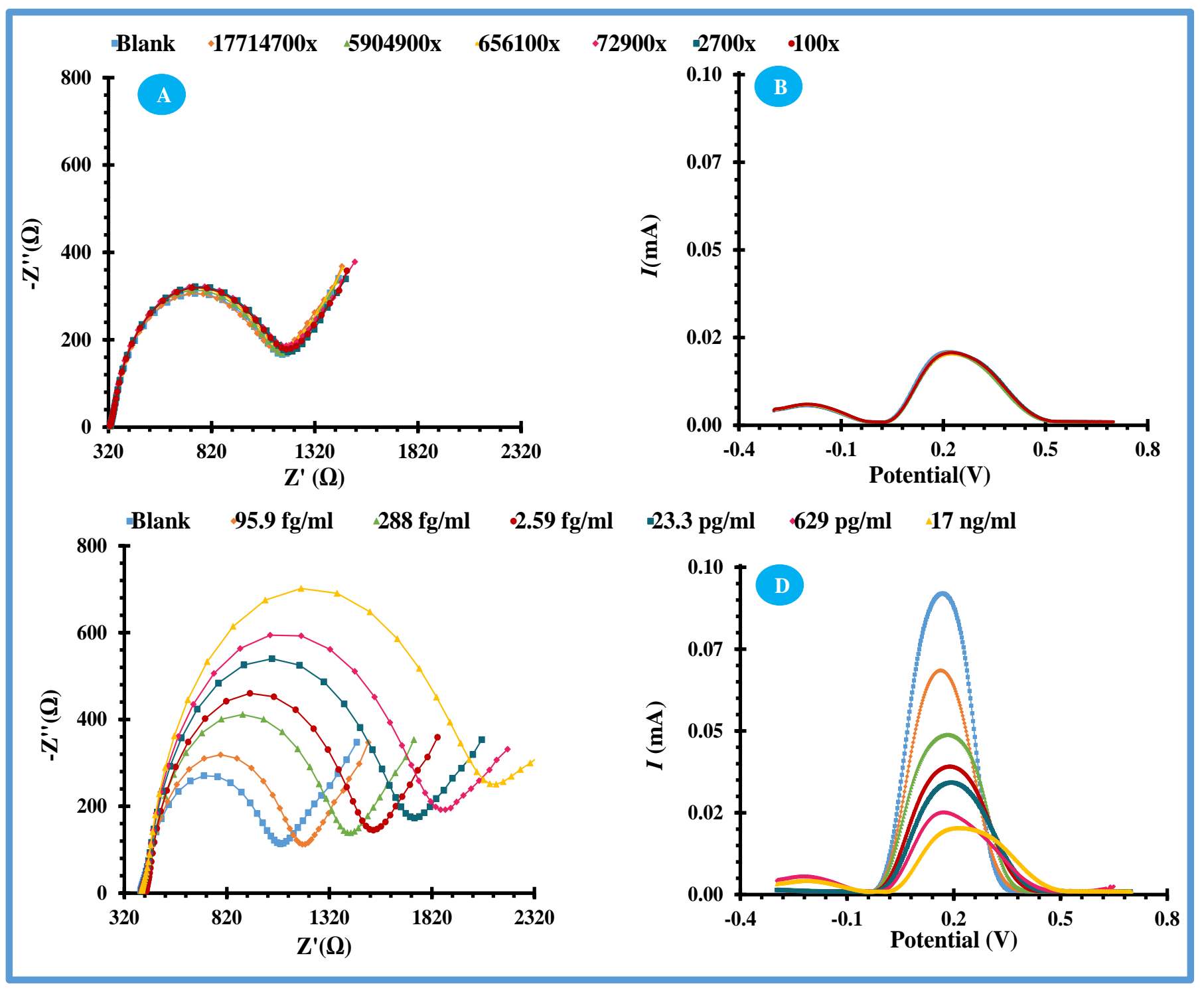

Figure 4 


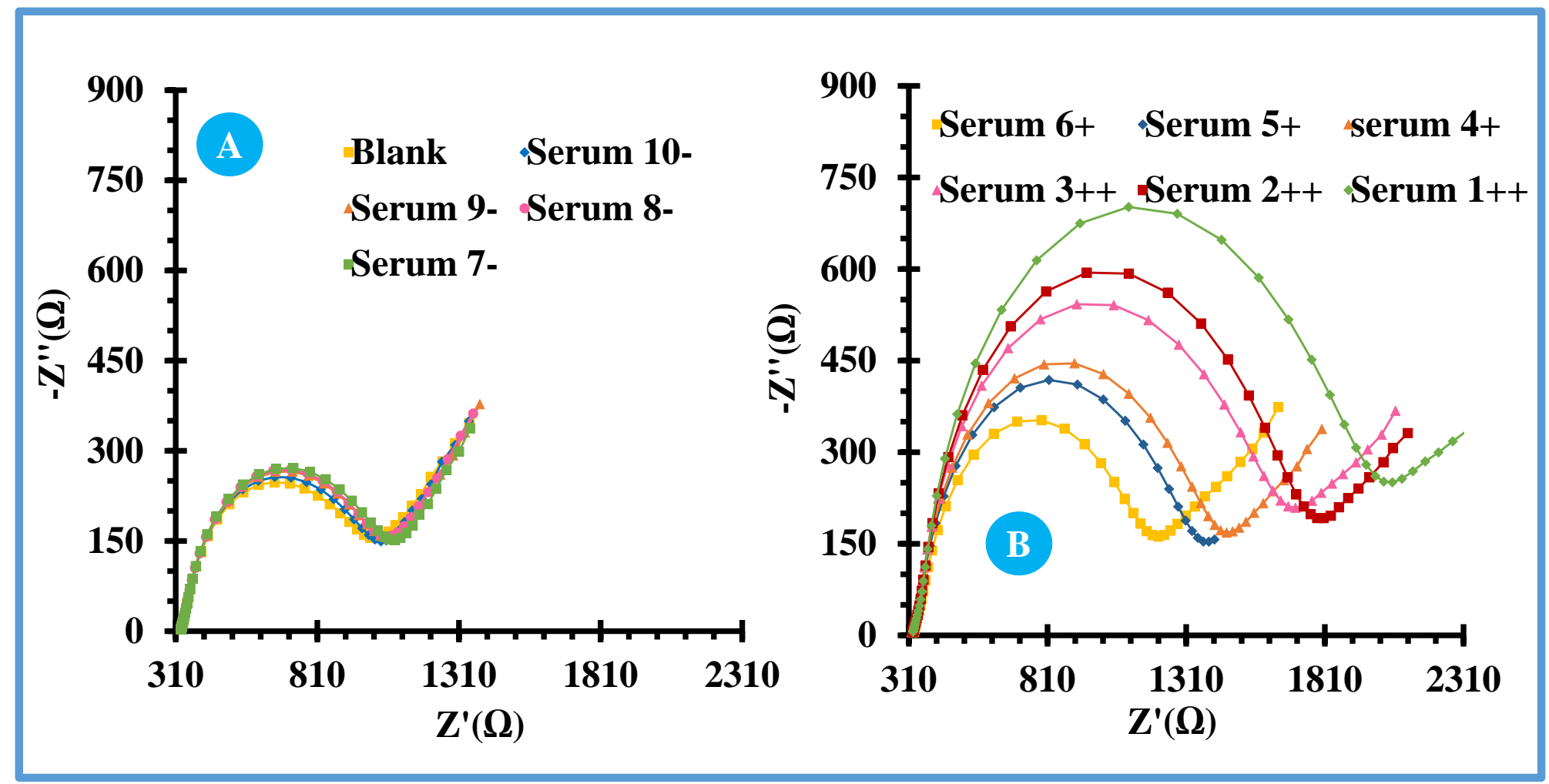

Figure 5 